\title{
Industri Radio Indonesia dalam Hegemoni Kapitalisme (Kajian Kritis Studi Media)
}

\author{
Okky Pramudhita1, Sujoko Anang ${ }^{2}$, dan Antoni*3 \\ ${ }^{1,2,3}$ Universitas Brawijaya \\ Email: okkypramudhita@gmail.com,@anangsujoko@gmail.com,@ant_ui@gmail.com* \\ *corresponding author
}

Keywords:

Radio

Contemporary hits radio

Media studies

Political economy communication

\begin{abstract}
This research is intended to elucidate the discourse of political economy in Indonesia radio industry. Nowadays, radio has became one of the profitoriented businesses and Contemporary Hits Radio (CHR) music format considered accomodating that purposes well. Nielsen' survey (2015) proves it by stating that radios using CHR music format settle in top positions on a chart based on the listeners in Jakarta. CHR music format plays trending popular songs, especially western songs, based on the global chart, like Billboards. While in fact, it is quietly strengthens the domination of major players in record label industry. They are Sony Music Entertainment, Warner Music Group, and Universal Music Group. To reveal this phenomenon, the researcher analyses the empirical data that consists of song chart in CHR music format radio in Indonesia, Nielsen's research data about radio rating in Indonesia, recording industry market share document along 2005 to 2011. This research basically explains that the economical interest has turned the radio to the tool of industrial mass culture by the major players in record label industry and its correlation with the capitalist system in music industry to create trending popular music.
\end{abstract}

\begin{abstract}
ABSTRAK
Penelitian ini pada dasarnya bertujuan untuk menggambarkan wacana ekonomi politik media pada industri radio di Indonesia. Saat ini, radio telah menjadi unit bisnis yang berorerintasi profit, format musik Contemporary Hits Radio (CHR) diangap mengakomodasi hal tersebut. Terbukti dari hasil survei Nielsen (2015) radio-radio dengan format musik CHR menempati beberapa posisi pendengar tertinggi di Jakarta. Format musik CHR memutarkan lagu yang sedang tren utamanya musik barat berdasarkan tangga lagu yang bersifat global seperti billboards. Padahal, secara tidak sadar justru memperkuat dominasi major players di industri label rekaman yaitu: Sony Music Entertainment, Warner Music Group, dan Universal Music Group. Untuk mengungkap fenomena ini peneliti menganalisis data-data empiris seperti tangga lagu radio-radio format musik CHR, hasil riset rating radio di Indonesia, serta market share industri rekaman rentan waktu 2005-2011. Penelitian pada dasarnya menjelaskan kepentingan ekonomi justru menjadikan radio menjadi alat industri budaya massa oleh major players di industri label rekaman serta hubunganya dengan lingkaran sistem kapitalisme dari industri musik sebagai alat menciptakan tren musik populer.
\end{abstract}

\author{
Kata Kunci: \\ Radio \\ Contemporary hits radio \\ Studi media \\ Ekonomi politik
}




\section{PENDAHULUAN}

Radio di Indonesia berawal sebagai alat perjuangan meraih kemerdekaan, sebut saja Bung Tomo atau presiden pertama Ir. Sorekarno menyebarkan semangat perjuangan melalui pidato-pidato di radio. Penyampaian pesan melalui radio dirasa lebih efektif karena, tidak memiliki jarak waktu sehingga pesan yang diterima masyarakat dapat diperoleh pada hari itu juga (Effendy, 2015).

Matelski (dalam Albarran, 1996) menyatakan bahwa radio merupakan media elektronik yang tertua, bermula pada tahun 1800-an kemudian pada perkembangannya dapat mencuri perhatian masyarakat dan mempengaruhi bagaimana masyarakat mendapatkan informasi ataupun hiburan. Berkembangnya penyiaran dunia dibagi menjadi dua bagian, yaitu media penyiaran sebagai penemuan teknologi dan media penyiaran sebagai industri (Morissan, 2008). Salah satu momentum radio di Indonesia menjadi industri ketika terbentuknya PRSSNI (Persatuan Radio Siaran Swasta Nasional Indonesia) di tahun 1996. Menurut Oramahi (2012) PRSSNI muncul dalam upaya perkembangan profesionalisme "radio amatir" yang dimotori oleh kaum muda dan para mahasiswa. Hiburan musik yang menyenangkan serta informasi yang disampaikan oleh penyiar di radio, masih menjadi alasan masyarakat modern untuk tetap mendengarkan radio. Menurut Effendy (2015) penyiaran informasi dalam bentuk berita dan penyiaran musik oleh radio dimulai hampir bersamaan. Bahkan ketika saya masih SMA, rela menunggu berjam-jam mendengarkan radio hanya untuk sekedar mendengarkan lagu dari musisi favorit saya.

Hingga saat ini, radio terus eksis dan berkembang menjadi industri media. Menurut Albarran (1996) radio merupakan industri media yang bersifat monopolistic competition, sehingga setiap radio berusaha mempunyai ciri yang spesifik dengan cara tertentu agar dapat dibedakan dari kompetitornya dengan harapan mendapatkan pendengar. Tentunya, dalam prespektif industri atau bisnis maka radio bersaing dengan berbagai sajian mulai dari program, penyiar, musik yang diputar, serta format siaran. Pringle, Starr, dan Mccavit (dikutip di Morissan, 2011) menyatakan dari berbagai macam format siaran radio, dapat dibagi tiga kategori format radio yaitu, radio format musik, radio format informasi, dan format khusus. Sedangkan menurut, Barnes (dikutip di Wallace, 1997) pemilihan musik sebagai format radio biasanya ditujukan untuk kepentingan bisnis. Hal ini menjadikan format musik menjadi pilihan bagi radio komersial salah satunya format CHR (contemporary hits radio). Vlad (2009) menyatakan Contemporary Hits Radio adalah radio format musik dengan target segmentasi utama remaja dan dewasa muda yang memutarkan musik-musik populer di tangga lagu dunia atau secara global.

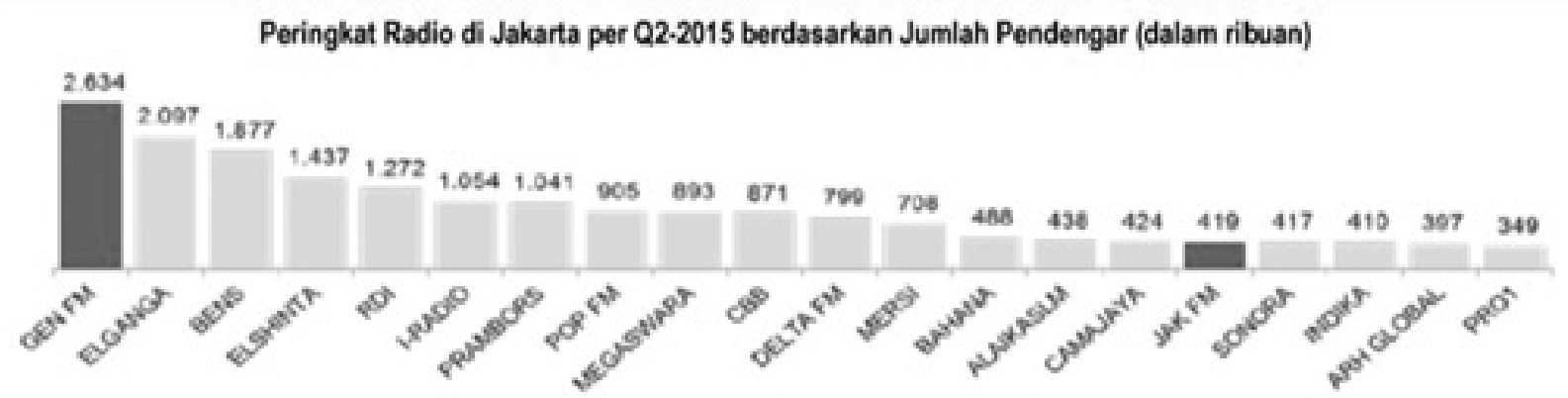

Gambar 1: Peringkat pendengar radio di Jakarta Sumber: Nielsen Media (2015)

Radio dengan format musik CHR menjadi tren radio-radio komersil di dunia termasuk juga di Indonesia. Menurut data dari Nielsen (2015), menggambarkan bagaimana format musik CHR sebagian besar digunakan oleh radio-radio dengan pendengar terbanyak di Jakarta dari total 20 radio terpopuler (diantaranya, Prambors, Pop Fm, Jak Fm, dan Indika). Data ini dapat menggambarkan bahwa format musik banyak dikaitkan dengan tujuan bisnis. Lewis (dikutip di Wallace, 1997, h.1) berpendapat bahwa format musik yang diputar pada radio dapat mempertahankan pendengar, karena musik tertentu yang diputar akan menyesuaikan pada komunitas tertentu yang menyukainya. Melalui format musik tertentu yang disesuaikan akan berpengaruh pada seberapa besar target khalayak yang diinginkan.

Pringle dan Starr (2006) menyebutkan bahwa, format musik Contemporary Hits Radio atau CHR yaitu radio yang utamanya memainkan musik atau lagu baru, beberapa lagu lama yang populer (oldies), radio dengan format musik ini mengutaman target pendengarnya pada kalangan remaja (teens). Musik atau lagu yang diputar juga mengikuti standar tangga lagu dari tangga lagu dunia seperti billboard Hot 100 Chart. Dengan minat yang tinggi dari masyarakan, radio format musik CHR seperti Prambors, Pop FM, dan Sonora di Jakarta, secara tidak langsung menciptakan tren musik tersendiri di Indonesia.

Di sisi lain, pemilihan format siaran musik, justru menjadikan radio sebagai industri budaya yang menguatkan musik atau lagu sebagai budaya populer. Kemudian, Garnham (1990) berpendapat bahwa media memainkan peran sebagai industri budaya, dianggap sebagai sistem produksi, distribusi, dan konsumsi simbol material maupun kultural. Budaya 
populer muncul karena ada sekelompok atau sejumlah orang membuat hal yang baru dan banyak diterima masyarakat luas (O’Brien \& Szeman, 2017). Radio secara tidak sadar membentuk musik atau lagu menjadi sebuah budaya pop. Padahal, tren musik tersebuth telah dikuasai oleh pihak-pihak distributor yaitu grup label rekaman raksasa. Hegemoni menurut Roger Simon (1999) bukanlah dominasi dengan menggunakan kekuasaan, melainkan hubungan persetujuan dengan menggunakan kepemimpinan politik dan ideologis, secara sederhana diartikan sebagai suatu konsensus organisasi. Dengan kata lain musik yang ada di radio dipengaruhi oleh kekuatan besar yaitu grup-grup label rekaman raksasa, namun mereka tidak pernah menyadarinya dan terus menambahkan pundi-pundi kekayaan label.

Penelitian mengenai industri label rekaman musik telah dilakukan sejak tahun 1990an. Menurut Albarran (1996) struktur pasar dari industri rekaman adalah oligopolistic yaitu terdapat beberapa perusahan saja yang menguasai pasar dan hanya bersaing dalam bentuk produk namun tidak bersaing pada harga. Menurut Trachtenberg (dikuti di Albarran, 1996) terdapat 6 perusahan yang disebut major players pada industri rekaman musik yaitu Warner, Sony Bmg, RCA, Philips, EMI, dan MCA pada tahun 1994.

Penguasaan Major Players terus berubah setiap tahun, seperti tahun 2005 Universal (dulunya MCA) menguasai pasar 31,71\% dengan pendapatan 7 miliar dollar, Sony BMG menguasai pasar 25\% dengan pendapatan 6 miliar dollar, Warner menguasai pasar 15\% dengan pendapatan 2,5 miliar dollar, EMI menguasai 9,55\% dengan pendapatan 4 miliar dollar, dan 18,13\% pasar terbagi pada label indie yang terdiri dari ratusan hingga ribuan label kecil yang tidak bersifat grup (Rez, 2005). Perkembangan industri rekaman, menggambarkan bahwa industri label rekaman terus mengalami pengerucutan kekuasaan.

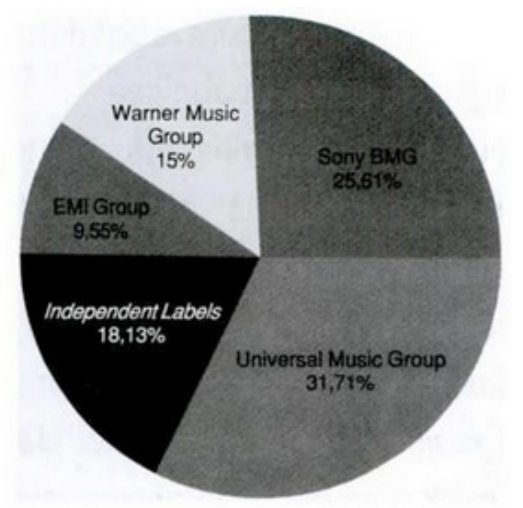

Gambar 2: Market Share musik global 2005 Sumber: Nielsen SounScan 2005 (Dikutip di Rez, 2005)

Dari data diatas, dapat diasumsikan radio di indonesia sebagai media mainstream secara tidak sadar memperkuat penguasaan Major Players industri label rekaman. Hal ini, sejalan dengan salah satu asumsi teori ekonomi politik, bahwa media media seringkali malah mendukung dan memelihara status quo (Subandy \& Ali, 2014). Penelitian ini bertujuan mengambarkan bagaimana fenomena menjamurnya radio format musik CHR di Indonesia secara tidak langsung berhubungan dengan sistem kapitalisme musik dunia, serta mengembangkan kajian ekonomi politik media terutama di Indonesia.

Istilah ekonomi politik didefinisikan Vincent Mosco (2009) dalam bukunya The Political Economy Of Communication sebagai hubungan kekuasaan yang saling menguntungkan pada sumber-sumber produksi, distribusi dan konsumsi, didalamnya akan saling berpengaruh komunikasi. Sedangkan, menurut (Baran \& Davis, 2010) kajian ekonomi politik bertujuan untuk mengkritik status quo, yang mengarahkan sebuah perubahan sosial. Pendekatan ekonomi politik media fokus pada kajian utama tentang hubungan antara struktur ekonomi-politik, dinamika media, dan ideologi media (McQuail, 2000).

Peneliti mencoba menelusuri tema kajian ekonomi politik radio secara khusus, di beberapa jurnal terkemuka, namun masih sulit. Adapun penelitian yang mendekati tema ini ekonomi politik radio yaitu buku Ben Bagdikian (2000) "The Media Monopoly" menjelaskan bagaimana perusahaan yang mengendalikan media-media besar amerika seperti radio, televisi, buku, serta film telah mengerucut dari 50an perusahan menjadi hanya 6 sejak tahun 1983 dan datanya berasal dari statistik-statistik industri media saat itu. Kajian ekonomi politik lainya mengenai televisi oleh Ade Armando (2006) meneliti sejarah privatisasi televisi di Indonesia tidak dipengaruhi oleh kepentingan kapitalisme global, namun oleh sekolompok kecil perusahan domestik yang dekat dengan penguasa politik saat itu yang pada akhirnya juga membuka ruang masuknya modal transnasional. Dalam penelitian Myer \& Kleck (2007) "From Independent to Corporate: A Political Economic Analysis of Rap Billboard Toppers" menggambarkan bagaimana kepemilikan label musik rap menjadi lebih terkonsentrasi, karena dipengaruhi kepemilikan 4 pemain besar di industri label yaitu Universal Music, Warner Music Group, Sony Music Group, dan EMI melalui data tangga lagu Billboard dari tahun 1990-2005. Hal ini mendasari, 
perlunya ada kajian secara khusus mengenai ekonomi politik radio di Indonesia maupun dalam skala global, mengingat masih sulitnya pencarian penelitang dengan tema-tema khusus seperti ini. Dari asumsi tadi penelitian ini nantinya menggunakan sudut pandang ekonomi politik untuk menjelaskan fernomena radio di indonesia serta kaitannya dengan kapitalisme musik global.

\section{METODE PENELITIAN}

Penelitian ini, berusaha menjabarkan wacana ekonomi politik media pada industri radio di Indonesia dengan menggunakan studi dokumentasi. Sugiyono (2009) menjelaskan bahwa studi dokumentasi merupakan suatu teknik pengumpulan data dengan cara mempelajari dokumen untuk mendapatkan data atau informasi yang berhubungan dengan masalah yang diteliti. Beberapa data yang dianalisis oleh peneliti yaitu tangga lagu radio-radio format musik CHR yang ada di Indonesia, data riset nielesen mengenai rating radio di Indonesia, dokumen market share industri rekaman rentan waktu 2005-2011. Dengan menganalisis data empiris, peneliti berusaha mengambarkan bagaimana keterkaitan industri radio di Indonesia dengan kapitalisme musik dunia.

\section{HASIL DAN ANALISIS}

\section{a. Komodifikasi}

Di era saat ini radio masih menjadi mainstream media bagi masyarat, dengan adanya industri maka akan ada konsumen dan pasar. Motif bisnis pada radio menjadikannya terikat pada struktur pasar tertentu. Vincent Mosco (2009) dalam bukunya The Political Economy of communication mengatakan ekonomi politik adalah tentang hubungan sosial, khususnya hubungan kekuatan, yang biasanya berbentuk produksi, distribusi, dan konsumsi dari sumber. Perusahanperusahan agensi iklan masih memasukan radio sebagai media promosi dan ada dalam perancangan pembelanjaan iklan produk-produk tertentu. Radio juga membutuhkan iklan untuk tetap berjalan, tentunya pengiklan akan mengukur efektivitas radio dari julmah pendengarnya. Maka hal inilah, yang akan terus mengikat radio dengan struktur pasar. Menurut Sudibyo, (2001) bahwa isi media lebih dipengaruhi oleh faktor ekonomi dan politik di luar pengelolaan media yaitu seperti, pemilik media, modal, dan pendapatan media dianggap lebih menentukan bagaimana isi sebuah media. Tentunya Radio format musik CHR dianggap paling mengakomodasi kebutuhan pasar. Data lembaga riset Nielsen (2017) menunjukan radio format musik Pop CHR terus mendominasi di industri radio amerika dan juga dunia. Format musik CHR menjadi pilihan utama bagi radio dengan tujuan bisnis, dengan alasan format ini lebih diinginkan oleh pendengar. Radio dengan format musik CHR sangat teratur dalam memainkan lagu-lagu populer yang menjadi ciri khas format ini. Musik atau lagu yang diputar juga mengikuti standar tangga lagu dari tangga lagu dunia seperti billboard Hot 100 Chart. Hal ini, menyebabkan radio merujuk pada pengukuran billboard musik-musik yang mancanegara atau barat menjadi mayoritas dan sisanya baru lagu indonesia menjadi pilihannya. Masuknya musik barat ke Indonesia diakomodasi oleh perkembangan radio swasta sejak awal orde baru, dan menjadikan musik barat sebagai daya tarik utama untuk khalayak muda di kota-kota besar (Armando, 2016). Dengan lebih diminatinya radio format musik CHR di kota besar seperti Jakarta mendorong pemilik radio-radio daerah pun merasa perlu mengikuti tren di Jakarta dan mengaplikasikan format musik CHR. Realita ini sejalan dengan salah satu asumsi teori Ekonomi Politik Media, dimana ada kontrol dari logika ekonomi menjadi faktor penentu utama bagi media (McQuail, 2010).

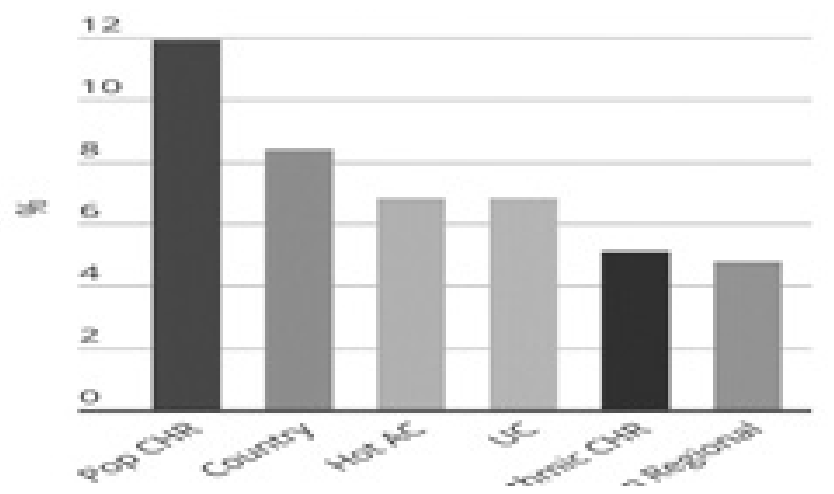

Gambar 3: Market peringkat tren format radio di Amerika maret 2017 Sumber: The Nielsen Company (2017)

Selain itu, Format musik CHR secara tidak langsung mendorong radio untuk menjadi pelaku komodifikasi. Menurut Mosco (2009) komodifikasi adalah proses perubahan barang dan jasa, terdapat dua tipe komodifikasi yang seringkali terjadi yaitu komodifikasi Isi (pesan atau komunikasi diperlakukan sebagai komoditas oleh media (seringkali terkait struktur kepemilikan atau terutama pada media global), Komodifikasi Khalayak (khalayak atau konsumen 
diperlakukan sebagai komoditas oleh media). Pada fenonema CHR radio melakukan kedua bentuk komodifikasi baik itu isi dan khalayak. Pertama, komodifikasi isi yaitu pada musik yang juga senjata utama dari radio format musik CHR, dijadikan sebagai daya tarik mendapatkan pendengar dengan tujuan ekonomi. Kedua, komodifikasi khalayak, dengan menggunakan format musik CHR radio berusaha untuk mendapatkan jumlah pendengar yang masif dengan tujuan sebagai legitimasi mereka kepada pengiklan. Hal ini menjadikan radio sebagai pelaku, namun hal ini juga dipengaruhi dominasi perusahan besar di industri rekaman yang memonopoli tren musik dunia.

Ibarat seperti jaring laba-laba radio telah terperangkap kedalamnya. Keberadaan radio-radio format CHR, semakin menguatkan dominasi major players di Indonesia dengan menjadi referensi tren musik barat. Ketiga label rekaman raksasa dunia ini hampir selalu menguasai peringkat 1-200 tangga lagu billboards dengan artis atau musisi yang bermacam-macam. Tren lagu populer dunia telah dikomodifikasi oleh pihak label rekaman menjadi bagian dari struktur pasar. Contohnya, seperti Lembaga peringkat musik billboards tidak akan ada banyak perbedaan dari peringkat 1 hinga 100. Musik populer telah dikuasai oleh major players sehingga produk musik mereka pasti ada di peringkat-peringkat tertenggi di lembaga riset karena hanya merekalah yang menguasai pasar tersebut.

Tabel 1. Tangga Lagu Radio format musik CHR di Jakarta

\begin{tabular}{|c|c|c|}
\hline \multirow{2}{*}{ Posisi } & Pramors & Sonora \\
\hline & Lagu \& label & Lagu \& label \\
\hline 1 & $\begin{array}{l}\text { Selena Gomez ft. Marshmello - Wolves } \\
\text { Universal }\end{array}$ & $\begin{array}{l}\text { David Guetta Ft. Justin Bieber - 2U } \\
\text { Warner }\end{array}$ \\
\hline 2 & $\begin{array}{l}\text { Hailee Steinfield ft. Alesso \& Florida } \\
\text { Georgia Line - Let Me Go } \\
\text { Universal }\end{array}$ & $\begin{array}{l}\text { Cheat Codes Ft. Demi Lovato - No promises } \\
\text { Warner }\end{array}$ \\
\hline 3 & \begin{tabular}{|l|} 
Nial Horan - Too Much To Ask \\
Universal
\end{tabular} & $\begin{array}{l}\text { Payung Teduh }- \text { Akad } \\
\text { Parara Record }\end{array}$ \\
\hline 4 & $\begin{array}{l}\text { Sheryl Shenafia ft. Rizky Febian \& Chandra } \\
\text { Liow } \\
\text { Trinty Optima }\end{array}$ & $\begin{array}{l}\text { Martin Garrix ft. Troye Sivan - There For you } \\
\text { Sony }\end{array}$ \\
\hline 5 & $\begin{array}{l}\text { Allan Walker ft. Noah Cyrus - All Fals } \\
\text { Down } \\
\text { Sony } \\
\end{array}$ & $\begin{array}{l}\text { Shawn Mendes - Theres No Holding Me Back } \\
\text { Universal }\end{array}$ \\
\hline 6 & $\begin{array}{l}\text { Clean Bandit ft. Julia Michaels - I Miss You } \\
\text { Warner }\end{array}$ & $\begin{array}{l}\text { Mytha Lestari - Begitulah } \\
\text { Sony }\end{array}$ \\
\hline 7 & \begin{tabular}{|l|} 
Rita Ora -Your Song \\
Sony
\end{tabular} & $\begin{array}{l}\text { Charlie Puth - Attention } \\
\text { Warner }\end{array}$ \\
\hline 8 & $\begin{array}{l}\text { Lauv - I Like Me Better } \\
\text { Independent }\end{array}$ & $\begin{array}{l}\text { Calvin Harris, Pharell Williams, Katy Perry, Big } \\
\text { Sean - Feels } \\
\text { Universal } \\
\end{array}$ \\
\hline 9 & $\begin{array}{l}\text { Bebe Rexha ft. Florida Georgia Line - Meant } \\
\text { To be } \\
\text { Warner }\end{array}$ & $\begin{array}{l}\text { Andien - Indahnya Dunia } \\
\text { Libaries Music }\end{array}$ \\
\hline 10 & $\begin{array}{l}\text { NF - Let You Down } \\
\text { Universal }\end{array}$ & $\begin{array}{l}\text { Tulus - Manusia Kuat } \\
\text { Tulus co }\end{array}$ \\
\hline
\end{tabular}

Sumber: Website Prambors (pramborsfm.com 6 Maret 2018) \& Website Sonora (sonora.do.id 10 November 2017)

Peneliti menggambil data Dari data tangga lagu radio-radio format musik CHR di jakarta antara Prambors dan Sonora memiliki kesamaan karena mengikuti standar billboard. Urutan Tanggal lagu ini juga dapat menggambarkan bagaimana pembagian kekuasaan di industri label tekaman dunia saat ini. Jika dijabarkan 5 lagu dari Label Universal menduduki peringkat teratas, 4 lagu dari label Warner menduduki peringkat teratas, 4 lagu dari label Sony menduduki peringkat teratas, dan sisanya berasal dari label independent. Dalam pandangan teori ekonomi politik salah satunya asumsinya adalah keanekaragaman yang sesungguhnya menurun (McQuail, 2010). Tangga lagu pada radio-radio format musik CHR terlihat sangat seragam, terdapat beberapa musik atau lagu dari musisi serta label yang sama. Hal ini menunjukan bahwa distribusi musik yang tidak seimbang karena dominasi major players antara lain Warner, Universal, dan Sony.

Teori Ekonomi politik juga berbicara struktur secara makro, bagaimana media dapat mempengaruhi tatan sosial secara keseluruhan (subandy \& Ali, 2014). Layaknya, seperti sebuah spiral yang tak berujung dan menyambung. Para major players telah menemukan pasar mereka di masyarakat, parahnya media juga memainkan perannya disana. Radio format musik CHR justru menjadi alat bagi major players Seperti Universal, Warner, dan Sony sebagai pencipta budaya massa sesuai keinginan mereka. Terlihat ironis memang, pada dasarnya radio hanya ingin mempertahankan kehidupan 
mereka sebagai media namun harus mengikuti keinginan pasar yang justru telah berada dibawah monopoli major players yang sudah mengakar secara ekonomi. Salah satu asumsi prespektif kritis adalah industri media saat ini membuat pekerja media tunduk oleh kepemilikan media dengan sistem saham yang hanya bertujuan secara ekonomi tanpa mengingat media sebagai "agen Pencerahan" (Armando, 2016). Radio terpaksa tak dapat menghindari kebutuhan "atas nama pasar" demi mempertahankan kehidupannya. Media seringkali terpaksa mengikuti keinginan pemilik modal, karena jika dipandang secara bisnis hal yang berbeda dengan kebutuhan pasar dianggap tidak menguntungkan. Hal ini sesuai dengan pendapat McQuail (2010) bahwa media yang independen akan semakin berkurang atau terpinggirkan, penanaman modal akan lebih berminat pada media yang dianggap menguntungkan secara pasar.

\section{b. Radio Sebagai Elemen Pendukung Status Quo}

Selain komodifikasi, dari sudut pandang teori ekonomi politik media dengan banyaknya radio-radio di Indonesia yang menggunakan format siaran musik CHR secara tidak langsung memperkuat sistem kapitalisme musik global. Para pemilik radio juga seakan menyetujui apa yang di inginkan pasar dan dengan sengaja merubah format radio menjadi lebih populer, dan format musik CHR dianggap mengakomodasi hal tersebut. Menurut McQuail (2010) sumber media yang independen akan semakin berkurang atau terpinggirkan, penanaman modal akan lebih berminat pada media yang dianggap menguntungkan secara pasar. Sayangnya, keinginan untuk memenuhi kebutuhan pasar oleh format musik CHR tidak sepenuhnya berawal dari keinginan radio tersebut, secara tidak sadar justru mereka terdesak oleh pasar itu sendiri.

Industri label rekaman sejak tahun 1996 dominasi grup-grup besar di industi musik terus mengerucut dan hanya dikuasi oleh sekelompok kecil saja.Musik atau lagu dari para major players industri label rekaman seperti Universal, Warner, dan Sony menguasi tangga lagu dunia seperti billboards atau tangga lagu global lainnya. Radio dengan format musik CHR memutarkan Lagu-lagu terkini dan bersifat populer dan trendy, karena segala yang bersifat trendy sangatlah menguntungkan (Masduki, 2004). Musik disebut sebagai budaya populer ketika musik memiliki standarisasi tertentu atau bersifat repetitif dan diterima begitu saja oleh audiens (Adorno, 2001).

\section{Record CompanyMarket Share}

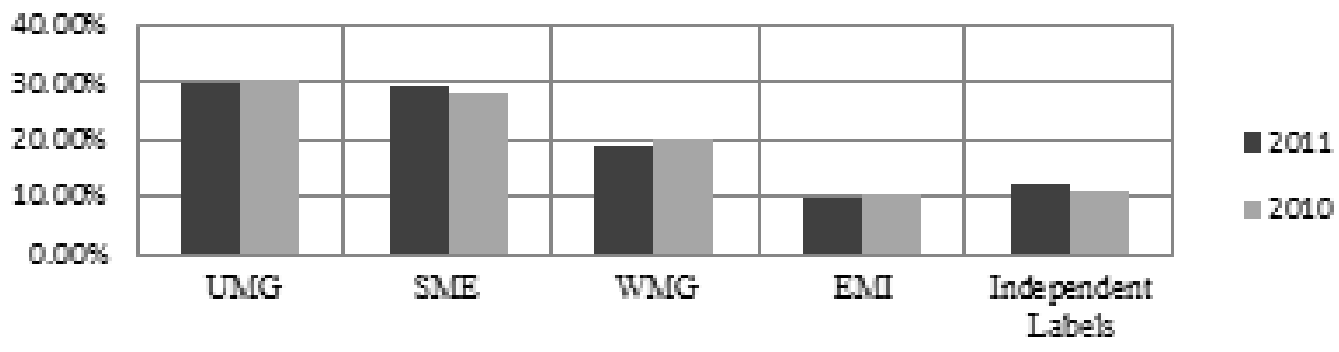

Gambar 4: Year-To-Date Record Company Market Share

Sumber: Nielsen SounScan 2011 (Dikutip di Hutchison, Macy \& Allen, 2009

Selama lebih dari satu dekade penguasaan Major Players tidak banyak berubah, data Nielsen 2011 menunjukan pergesaran penguasan pasar oleh ketiga raksasa ini tetap kokoh. Universal Music Group tetap sebagai juara dengan penguasan pasar 29.85\%, Sony Music Entertaiment (dulunya Sony BMG) menguasai 29.85\%, Warner Music Group menguasai 19.13\%, EMI menguasai 9.62\%, sedangkan sisanya adalah milik Independent labels 12.11\%. Dengan kata lain, penguasaan pasar di industri rekaman tidak banyak berubah major players tetap kuat dan eksis serta terus bersaing dengan para kompetior besar lainnya. Namun, Tepatnya di tahun 2012 EMI resmi mundur dari persaingan major players industri rekaman, perusahaan ini kemudian diakuisi oleh 3 major players yang tersisa diantaranya : Sony Music Entertainment (mengakusisi saham RCA), Warner Music Grup (mengakusisi Parlophone Records anak perusahan dari EMI), dan Universal Music Group (mengakuisisi Philips, dan sebagaian besar saham yaitu Capitol dan Virgin records). Perkembangan industri rekaman, menggambarkan bahwa beberapa ada beberapa perusahaan yang semakin dominan dan pembagian kekuasaan yang semakin mengerucut.

Kekuasaan pasar di industri rekaman label dikuasai hanya oleh sekelompok elit saja.Musik atau lagu yang diputar oleh radio-radio format musik CHR adalah lagu yang sudah didistribusikan secara masif oleh para major players label rekaman. Radio seakan tidak bisa keluar dari pola yang sudah diciptakan oleh major player selama bertahun tahun atau dengan kata format musik CHR tidak punya alternatif. Menurut Mansour (2002) menjelaskan hegemoni terkait pengaruh tentang konsep realitas sudut pandangan mereka yang mendominasi berhasil diterima oleh yang didominasi. Dalam hal ini tren musik para major players di pasar telah menjadi sesuatu yang umum bagi pemilik radio sehingga mereka secara tidak sadar telah mengakomodasi mereka melalui format musik CHR. 
Format musik CHR tidak langsung semakin menguatkan tren musik populer barat yang sudah berada dalam genggaman major players. Di Indonesia saat ini, radio hanya mendapatkan distribusi lagu asing dari label besar yang berlisensi di negara kita yaitu Universal, Warner, dan Sony. Ketiga label besar ini secara resmi mendistribusikan lagulagu barat atau asing ke hampir seluruh radio di Indonesia, dengan kata hanya lagu mereka yang diputari di Indonesia. Hal ini sejalan dengan salah satu satu proposisi teori ekonomi politik media, yaitu akses pada keuntungan komunikasi tersebar secara tidak merata dan hanya dinikmati oleh kelompok dominan (McQuail, 2010). Universal, Warner, dan Sony juga selalu menguasai peringkat 1-200 tangga lagu billboards dengan artis atau musisi yang bermacam-macam atau sederhananya mereka menguasai tren tangga lagu secara global. Menurut Armando (2016) tema umum dari teori media kritis adalah bahwa produk media tidak dapat menghindari untuk memperkuat status quo, serta mengesampingkan usaha perubahan sosial yang konstruktif.

Keberadaan radio-radio format CHR ini semakin melegitimasi dominasi major players dengan menjadikan musik atau lagu mereka menjadi tren juga di Indonesia. Menurut Baran \& Davis (2010) kajian ekonomi politik untuk mengkritik status quo, yang mengarah pada perubahan sosial. Media mainstream secara tidak sadar dihegemoni oleh kekuatan besar, yaitu kapitalisme global. Kehadiran format musik CHR adalah keinginan pasar, dan tren pada pasar tersebut diciptakan oleh major players yang siap menggelontorkan dana dalam jumlah besar untuk tetap mendominasi pasar yang mereka sengaja ciptakan sendiri.Gagasan teori ekonomi politik berawal dari gagasan marxis, penafsiran karl marx bahwa media masa sebagai bagian penting dari instrumen kaum penguasa untuk mengontrol atau mempertahankan status quo (Armando, 2016).

Radio menganggap lagu yang mereka mainkan adalah apa yang diingkan oleh masyarkat, namun pandangan seperti ini juga dipengaruhi oleh major players di industri rekaman dengan kekuasaannya pada struktur pasar. Teori ekonomi politik juga digunakan sebagai pendekatan kritik sosial yang fokus hubungan struktur dan dinamika industri media serta konten ideologis media, media dianggap sebagai bagian dari sistem ekonomi dan terkait dengan sistem politik (Andy \& Subandy, 2014). Kepentingan ekonomi justru menjadikan radio menjadi alat industri budaya massa oleh major players di industri label rekaman. Fenomana format musik CHR berada dalam lingkaran sistem kapitalisme dari industri musik sebagai alat menciptakan tren musik populer. Pada dasarnya pendapat teori kritis bahwa media seringkali malah mendukung dan memelihara status quo (Subandy \& Ali, 2014). Seperti permainan ular memakan ekornya sendiri terus mengejar namun tak ada habisnya, radio format musik CHR dan industri rekaman saling terikat satu sama lain mengukuhkan sistem kapitalisme yang kuat. Sesuai tafsir karl marx tentang media sebagai bagian penting dari instrumen kaum penguasa untuk mengontrol atau mempertahankan status quo (Armando, 2016). Terdapat pengaruh kekuasaan dari major players di industri rekaman yang berkesinambungan dari musik atau lagu yang diputar oleh radio format musik CHR dan keinginan pasar atau nilai ekonomi serta monopoli tren musik.

\section{KESIMPULAN}

Teori-teori ekonomi politik media mengasumsikan bahwa industri media tidak akan lepas dari hegemoni kapitalisme global, termasuk di Indonesia. Tren musik yang kita dengarkan di radio ternyata tidak lepas dari proses komodifikasi padahal, musik seringkali dianggap sebagai seni yang universal yang bebas nilai. Atas kebutuhan bisnis radio dengan format musik CHR akan dipilih justru terus memperkuat major players di industri rekaman. Penelitian ini mencoba menyadarkan common sense kita tentang musik atau lagu yang menjangkau berbagai kalangan ternyata dikuasai oleh sekolompok kecil perusahaan saja. Selanjutnya, diharapkan penelitian ini dapat menjadi pijakan penelitian lain menyoal industri radio di Indonesia dari sudut pandang kritis yang cenderung masih sedikit terutama pada wilayah makro.

\section{DAFTAR PUSTAKA}

Adorno, T. W. (2001). The culture industry. London and New York : Routledge.

Albarran A. B. (1996). Media Economics Understanding Markets, Industries and Concept. Ames: Iowa State University Press.

Armando, A. (2016). Televisi Indonesia di Bawah Kapitalisme Global. Jakarta:Kompas.

Armando, A. (2006). Privatisasi Pertelevisian Indonesia Antara Dinamika Interntal dan Perkembangan Global. Universitas Indonesia.

Bagdikian, B. H. (2000). The Media Monopoly, 6th Edition. Boston: Beacon Press.

Baran, S. J., \& Davis, D. K. (2010). Teori Komunikasi Massa: Dasar, Pergolakan, dan Masa Depan. Jakarta: Salemba Humanika.

Effendy, U. O. (2015).Dinamika Komunikasi. Bandung: Remaja Rosdakarya.

Garnham, H. (1990). Capitalism and Communication: Global Culture and Economics of Information. London: Sage. 
Hutchison, T. W., Macy, A., \& Allen, P. (2009). Record label marketing. Burlington, MA : Focal Press.

Masduki. (2004). Menjadi Broadcaster Profesional. Jogjakarta: Pustaka Populer LkiS.

Mansour, F. (2002). Runtuhnya Teori Pembangunan dan Globalisasi. Yogyakarta: Pustaka Pelajar.

McQuail, D. (2010) McQuail's Mass Communication Theory (6th ed.). London: Sage.

Mosco,V. (2009). The Politcal Economy of Communication. London: Sage.

Morissan, M. A. (2008). Manajemen Media Penyiaran: Strategi Mengelola Radio \& Televisi. Jakarta: Kencana.

Myer, L., \& Kleck, C. (2007). From Independent to Corporate: A Political Economic Analysis of Rap Billboard Toppers. Popular Music and Society, 30-2.

Nielsen. (2015). Peringkat pendengar radio di Jakarta. Diambil dari Website Nielsen 14 Januari 2016 http://www.nielsen. com/id/en/solutions/audience-measurement.html.

Nielsen. (2017). Reflecting on the u.s. radio listening trends of the first quarter. Diambil dari website Nielsen 26 April 2017 : http://www.nielsen.com/us/en/insights/news/2017/reflecting-on-the-us-radio-listening-trends-of-the-firstquarter.html

Oramahi, H. A. A. (2012). Jurnalistik Radio: Kiat Menulis Berita Radio. Jakarta: Erlangga.

Prambors. (2018). Chart Top 40. Diambil dari website prambors 6 Maret 2018 : http://www.pramborsfm.com/charts

Pringle, P., \& Starr, M. (2013). Electronic Media Management. Burlington: Focal Press.

Simon, R. (1999). Gagasan-gagasan Politik Gramsci. Yogyakarta : Pustaka Pelajar dan Insist.

Sudibyo, A. (2001). Politik Media dan Pertarungan Wacana. Jogjakarta: PT LKIS Pelangi Aksara.

Sugiyono. (2009). Metode Penelitian Kuantitatif, Kualitatif dan R\&D. Bandung : Alfabeta.

Sonora. (2018). Sonora Chart. Diambil dari website Sonora 10 November 2017 http://sonora.co.id/sonora_chart

Szeman, I., \& O’Brien, S. (2017). Popular culture: A user's guide. New Jersey : John Wiley \& Sons, Inc.

Vlad, D. (2009). The Main Music Radio Formats in Romania Today. Revista de Stiinte Politice. Revue des Sciences Politiques, 21-22.

Wallace, J. (1997). Radio Formats and the Transformation of Musical Style: Codes and Cultural Values in the Remaking of Tunes. College Music Symposium, 37. 